\title{
Dermatite associada ao consumo de farelo de arroz desengordurado em bovinos ${ }^{1}$
}

\author{
Juliana S. Brum², Tessie B. Martins², Bianca Tessele², Paula R. Giaretta ${ }^{3}$, \\ Franklin Riet-Correa ${ }^{4}$ e Claudio S.L. Barros ${ }^{5 *}$
}

\begin{abstract}
Brum J.S., Martins T.B., Tessele B., Giaretta P.R., Riet-Correa F. \& Barros C.S.L. 2012. [Dermatitis associated with consumption of defatted rice bran in cattle.] Dermatite associada ao consumo de farelo de arroz desengordurado em bovinos. Pesquisa Veterinária Brasileira 32(7):627-632. Departamento de Patologia, Universidade Federal de Santa Maria, Camobi, Santa Maria, RS 97105-900, Brazil. E-mail: claudioslbarros@uol.com.br

Dermatitis has been observed in Uruguay and Rio Grande do Sul, in cattle supplemented with defatted rice bran in an amounts equivalent to $1 \%$ of body weight. An outbreak of dermatitis in cattle associated with consumption of defatted rice bran in Rio Grande do Sul, is herein described. Out of a total of 263 -year-old cattle consuming this ration, seven had lesions that were observed after 24 days on the ration. The lesions were observed in the distal hind limbs and were characterized by areas of alopecia with marked thickening of the epidermis with crust formation imparting a thicken and fissured aspect to the skin. The histological lesions observed in these cases were characterized as moderate superficial perivascular chronic dermatitis focally extensive, with irregular acanthosis and serocellular crusting. The gross lesions observed, together with epidemiological data, allow for a diagnosis of dermatitis associated with the consumption of defatted rice bran. Histologic changes, although not pathognomonic, are typically described in this disease.
\end{abstract}

INDEX TERMS: Cattle diseases, skin diseases, dermatitis, hypersensitivity, rice bran.

RESUMO.- Dermatite tem sido observada em bovinos no Uruguai e no Rio Grande do Sul que são suplementados com farelo de arroz desengordurado em quantidade equivalente a $1 \%$ do peso corporal. Descreve-se um surto de dermatite associada ao consumo de farelo de arroz desengordurado em um município do interior do Rio Grande do Sul. Do total de 26 bovinos, com três anos de idade, sete apresentaram lesões que foram observadas após 24 dias de ingestão da ração de farelo de arroz desengordurado. As lesões eram observadas na extremidade distal dos membros

\footnotetext{
${ }^{1}$ Recebido em 3 de fevereiro de 2012.

Aceito para publicação em 28 de fevereiro de 2012.

${ }^{2}$ Programa de Pós-Graduação em Medicina Veterinária, área de concentração em Patologia Veterinária, Centro de Ciências Rurais, Universidade Federal de Santa Maria (UFSM), Camobi, Santa Maria, RS 97105-900, Brasil.

${ }^{3}$ Bolsista de Iniciação Cientifica PIBIC/CNPq do Laboratório de Patologia Veterinária da UFSM, Santa Maria, RS.

${ }^{4}$ Laboratório de Patologia Animal, Centro de Saúde e Tecnologia Rural (CSTR). Universidade Federal de Campina Grande (UFCG), Patos, PB 58700-00, Brasil.

${ }^{5}$ Laboratório de Patologia Veterinária, UFSM, Camobi, Santa Maria, RS. *Autor para correspondência: claudioslbarros@uol.com.br
}

posteriores e se caracterizavam por áreas de alopecia, com acentuado espessamento da epiderme, formando crostas secas, espessas e fissuradas. A lesão histológica observada nestes casos foi caracterizada como dermatite perivascular superficial crônica focalmente extensa moderada, com acantose irregular e formação de crosta serocelular. As lesões macro e microscópicas observadas, juntamente com os dados epidemiológicos, permitem concluir o diagnóstico de dermatite associada ao consumo de farelo de arroz desengordurado. As lesões histológicas, embora não patognomônicas, são descritas nesta doença.

TERMOS DE INDEXAÇÃO: Doenças de bovinos, dermatopatias, dermatite, hipersensibilidade, farelo de arroz.

\section{INTRODUÇÃO}

A industrialização do arroz produz uma série de subprodutos, entre eles o arroz integral, do qual, após a extração do óleo, obtém-se o farelo de arroz desengordurado (Leite, 2006), que apresenta como principal vantagem a não rancificação permitindo que o produto seja armazenado por um período de tempo maior (White \& Hembry 1985, Prasad et al 1990). Para ruminantes suplementados a campo ou con- 
finados, é uma importante alternativa, principalmente nas regiões produtoras de arroz. Acredita-se influenciar positivamente na digestibilidade e incrementar o ganho de peso (Garcia et al 1992, Forster et al 1994).

Dermatite tem sido observada no Uruguai (Dutra \& Cesar 2000) e no Rio Grande do Sul (Schild et al 1997) em bovinos que são suplementados com farelo de arroz desengordurado (FAD). É caracterizada por lesões de pele localizadas, preferencialmente nos membros posteriores (Schild 2007). Como na maioria das doenças alérgicas, bovinos adultos são mais susceptíveis (Walton 1971, Barratt \& Porter 1979, Schild 2007, Hensel 2010) e a probabilidade de adquirirem a doença é 42 vezes maior do que em animais com menos de 2 anos de idade (Schild 2007).

Acredita-se que a enfermidade seja produzida devido a uma hipersensibilidade alimentar em consequência do alto nível proteico que existe neste alimento (Belyea et al 1989, Dutra 1998). Em ruminantes, algumas proteínas pouco solúveis não são degradadas no rúmen, passando diretamente ao intestino e sensibilizando o animal (Dutra \& Cesar 2000), semelhantemente ao que é descrito para a hipersensibilidade ao farelo de soja em porcos e bovinos (Li et al 1990). Os bovinos afetados melhoram após a retirada da alimentação e tornam a apresentar lesões quando o farelo é novamente administrado, demonstrando uma suscetibilidade individual ao aparecimento das lesões (Schild 2007).

Este trabalho descreve os achados epidemiológicos, clínicos, hematológicos e histológicos observados na dermatite associada ao consumo de farelo de arroz desengordurado, através do relato um surto da doença ocorrido em município do interior do Rio Grande do Sul, acrescentado das informações que já se conhece sobre a doença.

\section{MATERIAL E MÉTODOS}

Foi realizada visita a uma propriedade rural, situada no distrito de Azevedo Sodré ((latitude $30^{\circ} 07^{\prime} S$, longitude $54^{\circ} 38^{\prime} 0$ ) que pertence ao município de São Gabriel no Rio Grande do Sul. Dados da doença clínica e manejo dos bovinos foram observados e coletados juntamente com o proprietário.

A avaliação se deu em um lote constituído por 26 bovinos, machos castrados, de três anos de idade, cruzados, com peso médio de $320 \mathrm{Kg}$ que estavam em pastagem de braquiária com cinco anos de implantação (brisanta e MG-5). Há 24 dias eram suplementados com ração peletizada, tipo manutenção. Pela manhã 5 $\mathrm{kg}$ de proteinado energético eram adicionados à ração.

A quantidade de ração diária era de $80 \mathrm{Kg}$ para todo o lote. A ração era constituída de farelo de arroz desengordurado estabilizado (69\%), contendo aproximadamente $140 \mathrm{~g} / \mathrm{kg}$ de proteína. Metade do montante, em forma de pellets com aproximadamente $7,0 \mathrm{~mm}$, era colocado no coxo pela manhã e a outra metade, à tarde.

Nos bovinos em que foram observadas lesões, realizou-se exame clínico específico da pele. Foram colhidos $6,0 \mathrm{~mL}$ de sangue da jugular de todos os afetados e de outros quatro animais não afetados do mesmo lote. Para realização do hemograma, que incluía eritrograma e leucograma, foram utilizados $3,0 \mathrm{~mL}$ de sangue acondicionado em tubos com o anticoagulante ácido etilenodiaminotetracético (EDTA). Para determinação das concentrações de proteínas plasmáticas totais, albumina, proteinograma e concentração de imunoglobulina E (IgE) foi utilizado o soro de $3,0 \mathrm{~mL}$ de sangue acondicionados em tubos sem anticoagulante. Os métodos utilizados para determinação das proteínas, albumina, proteinograma e IgE foram, respectivamente, biureto, verde de bromocresal e eletroforese capilar (Sebia) e nefelometria.

Em um dos bovinos foi realizada sedação com xilazina $(0,05 \mathrm{mg} / \mathrm{kg})$ e contenção. Bloqueio anestésico local com cloridrato de lidocaína $(7,0 \mathrm{mg} / \mathrm{kg})$ foi feito na região distal do membro posterior direito. Com o auxílio de um bisturi noำ e pinça de Adson $\mathrm{n} \times 12$ dente de rato foi retirado um fragmento de pele com aproximadamente 1,5 x 1,5 x 0,4cm. Em outros dois pontos adjacentes, com um auxílio de um punch (manobra de Whyte e Perry) foram retirados dois fragmentos de pele de $6,0 \mathrm{~mm}$ de diâmetro cada. 0 local das incisões foi higienizado com iodo a $10 \%$ e tratado com spray cicatrizante comercial. Os fragmentos foram fixados em formol a $10 \%$, processados rotineiramente para histopatologia, corados pela hematoxilina e eosina e a técnica histoquímica do Azul de Toluidina.

Para realização do teste intradérmico utilizou-se um extrato constituído de ração constituída de FAD diluída em cloreto de sódio $(0,15 \mathrm{~N})$. Este foi incubado em estufa com temperatura controlada a $40^{\circ} \mathrm{C}$ por 24 horas. Após, foi centrifugado por 15 minutos a 2.000 RPM. A fração sobrenadante foi separada. A dosagem da proteína desta solução era de $6 \%$. Trinta dias após a observação dos sinais clínicos, $0,02 \mathrm{~mL}$ foram injetados da prega caudal de dois bovinos que desenvolveram a doença e em um bovino sadio do mesmo lote, posteriormente a medição da prega com auxílio de um cutímetro (denominado tempo zero - T0). Após uma hora (T1) e duas horas (T2) foram realizadas novas medições, da mesma forma.

\section{RESULTADOS E DISCUSSÃO}

Do total de animais examinados neste surto (26), todos com três anos, sete bovinos (26,9\%) apresentaram lesões. No Uruguai (Dutra 1998) foi observado que a taxa de morbidade para novilhos com a doença foi entre 10 e 90\%. Essa taxa é menor e tem menor amplitude quando os animais têm até um ano de idade (5-25\%) e pode chegar aos $100 \%$ quando se trata de vacas de leite (Schild 2007). De acordo com a idade dos animais deste estudo e a categoria que se encontram, pode-se observar que a morbidade está dentro do esperado.

A inclusão do FAD na dieta de ruminantes deve ser limitada a $1,5 \mathrm{~kg} /$ dia para vacas em lactação, $20 \%$ das rações para bezerros e até $40 \%$ nas de animais em engorda (Costa et al 2005). Em um trabalho com diversas concentrações de FAD (Leite 2006), observou-se que bovinos suplementados com $0,75 \%$ do peso vivo, além de não apresentarem ganho de peso médio diário satisfatório, desenvolveram laminite, que, naquele trabalho, foi considerada uma consequência de acidose ruminal crônica.

Uma análise em diferentes amostras de FAD produzida em várias partes do mundo revelou que no Brasil e no Uruguai, onde a doença é relatada, o método de extração do óleo é similar e que, nesses países, o FAD apresenta menor degradabilidade ruminal da fração proteica (Dutra 1998). Isto provavelmente esteja relacionado com as características físico-químicas do FAD peletizado. A temperatura e pressão associadas com o processo de extração de óleo e posterior peletização produzem materiais menos suscetíveis à degradação pelas bactérias ruminais (Ørskov \& McDonald 1979, Garcia et al 1993), aumentando o escape de proteínas para os intestinos, permitindo a sensibiliza- 
ção do animal (Walton 1971, Van Dijk et al 1988, Zinn et al 1988, Cianferoni \& Spergel 2009). Não se sabe qual fração proteica é responsável pela hipersensibilidade.

Os estudos realizados no Uruguai descrevem alguns fatores de risco entre o consumo do FAD e o desenvolvimento da doença (Dutra 1998). Observou-se que os limites entre a porcentagem ingerida é bastante amplo: de 0,4 a $1,4 \%$ de peso vivo, e que a morbidade varia dependendo da idade dos animais. Animais que comem o FAD há mais tempo tem menos chance de desenvolver a doença, porém quando há mudanças bruscas nos níveis da suplementação, esta chance aumenta significativamente. Em uma ração comercial o volume diário indicado é $0,8 \%$ do peso vivo (PV), com período de adaptação crescente de dez dias (Irgovel s/d). No lote de bovinos aqui estudados, a quantidade de ração fornecida ao lote correspondia a aproximadamente $0,96 \%$ do peso corporal para cada animal. Esta quantidade foi administrada desde o início do fornecimento da ração, sem nenhum período de adaptação.

A enfermidade se desenvolve entre 15 e 120 dias (média de 35 dias) depois do início da administração do FAD (Dutra \& Cesar 2000). Neste estudo as lesões foram observadas após 24 dias de ingestão do FAD. Porém já se apresentavam em estágio crônico, algumas com infecção bacteriana secundária $(28,6 \%$ dos animais). No outro surto descrito (Dutra \& Cesar 2000) observaram uma taxa de $22 \%$ de infecção secundária. Em nenhum momento foi observado prurido ou perda do apetite, assim como é descrito (Schild 2007).

De acordo com a literatura, o processo se inicia na região da coroa e face flexora da quartela de ambos os membros posteriores e logo alcança a região do boleto (Dutra 1998). 0 mesmo autor relata que inicialmente a região apresenta-se edemaciada, com eritema e exsudação; os membros estão aumentados de volume e alguns animais podem ter dificuldade em se locomover. Em um dos animais deste surto podiam se observar áreas elevadas e papulosas em toda a extensão dos membros anteriores, interpretadas como urticária.

Em geral a enfermidade se limita as partes baixas dos membros posteriores (Fig.1). Ocasionalmente podem ser

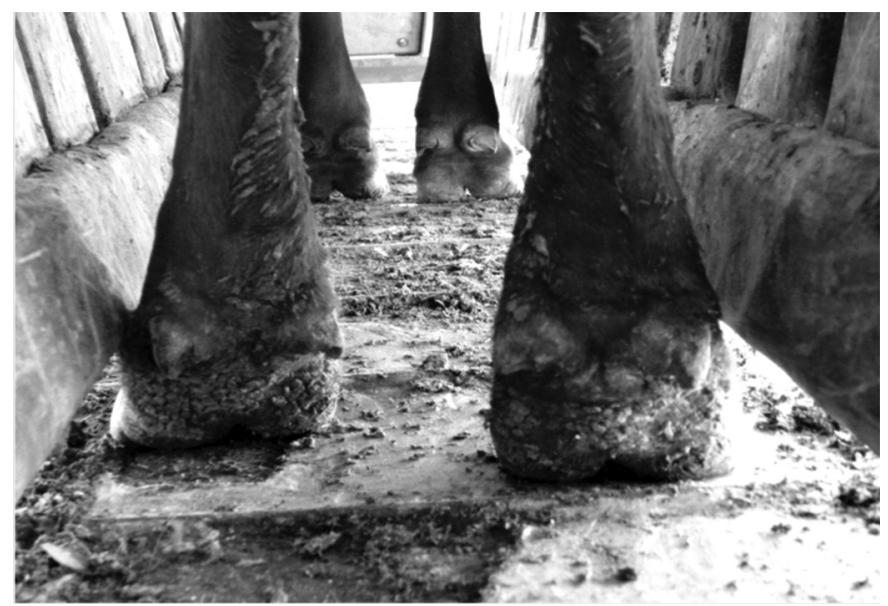

Fig.1. Dermatite em bovino associada ao consumo de farelo de arroz desengordurado. Observam-se lesões quase que restritas aos membros posteriores. vistas nos membros anteriores. Casos com lesões generalizadas são vistos em animais adultos, principalmente em vacas leiteiras e novilhos em terminação (Dutra \& Cesar 2000). Todos os sete bovinos afetados neste surto apresentavam lesões em ambos os membros posteriores (Fig.2), com diferentes graus de intensidade. Em dois animais as lesões foram classificadas como acentuadas; em três bovinos foram ditas moderadas já em regressão; e em dois animais as lesões eram mais intensas em apenas um dos membros posteriores. Um bovino apresentava lesão também nos membros anteriores, de intensidade leve.

Macroscopicamente as lesões caracterizavam-se por áreas multifocais ou focalmente extensas de alopecia, com acentuado espessamento da epiderme, formando crostas secas, espessas e fissuradas (Fig.3). Estas eram observadas predominantemente na face plantar (Fig.4), ao redor da coroa do casco (Fig.5), estendendo-se proximalmente em proporções variáveis até a região do dígito acessório (Fig.6). Segundo a literatura, a exsudação causa aglutinação dos pelos e formação de crostas úmidas e aderentes com

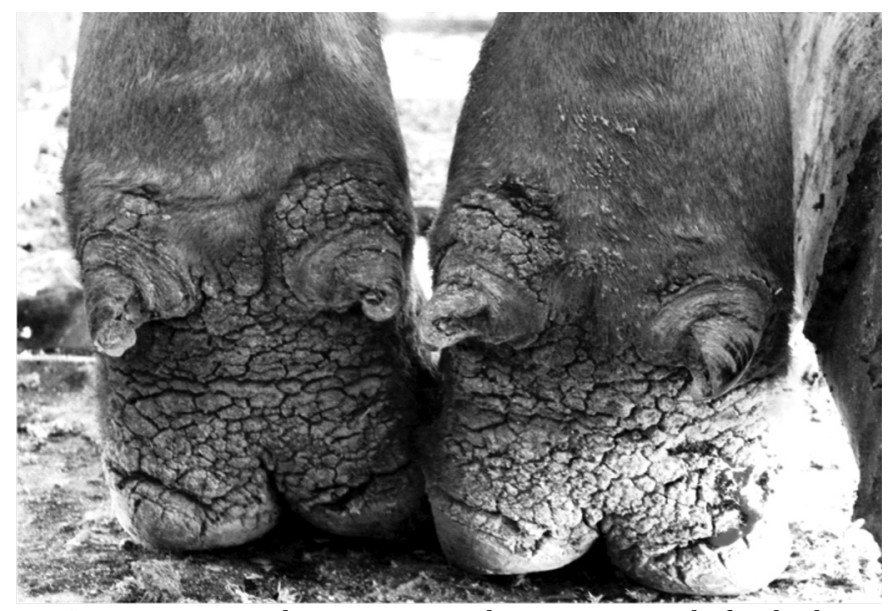

Fig.2. Dermatite em bovino associada ao consumo de farelo de arroz desengordurado, apresentando lesão em ambos os membros posteriores e de intensidade acentuada.

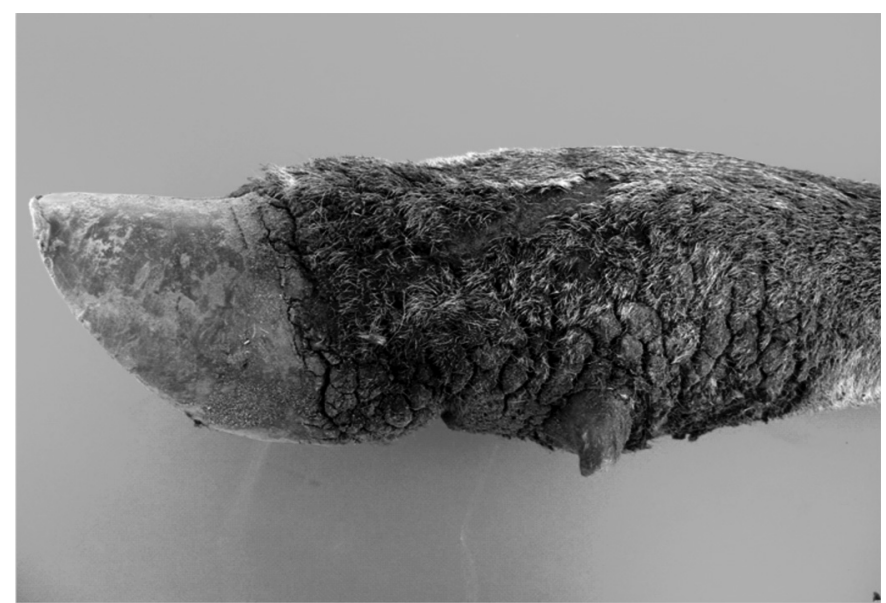

Fig.3. Dermatite em bovino associada ao consumo de farelo de arroz desengordurado. As lesões caracterizam-se por áreas de alopecia, com espessamento da epiderme, formando crostas secas, espessas e fissuradas. 


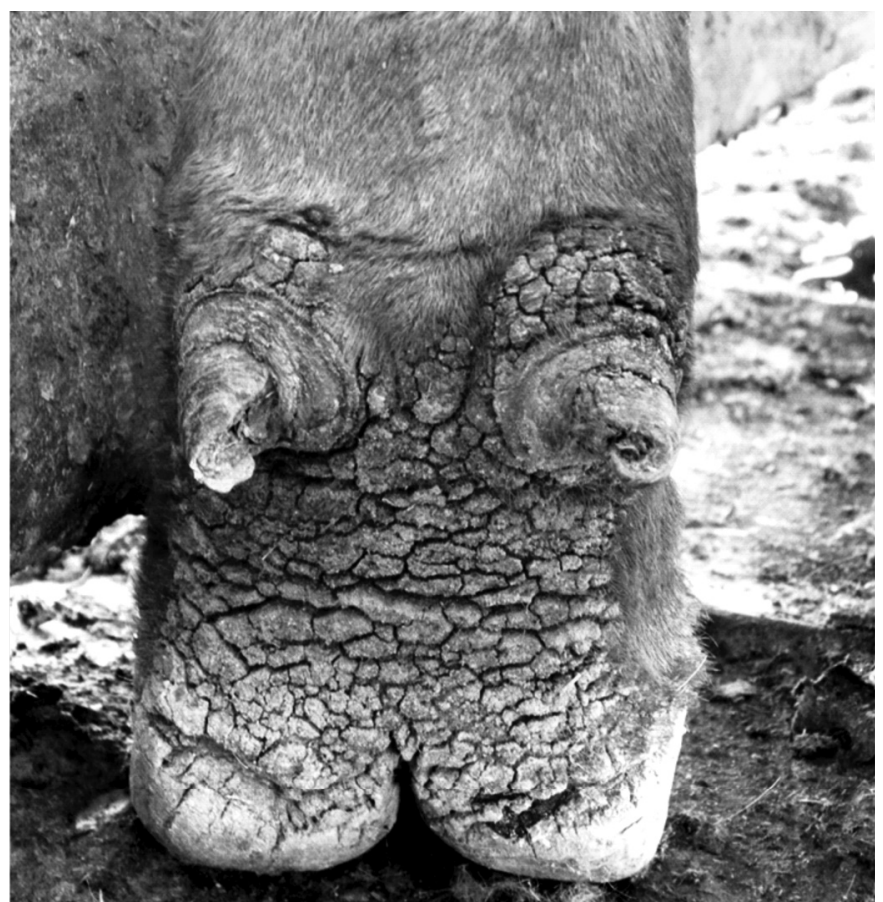

Fig.4. Dermatite em bovino associada ao consumo de farelo de arroz desengordurado. Lesões observadas predominantemente na face plantar.

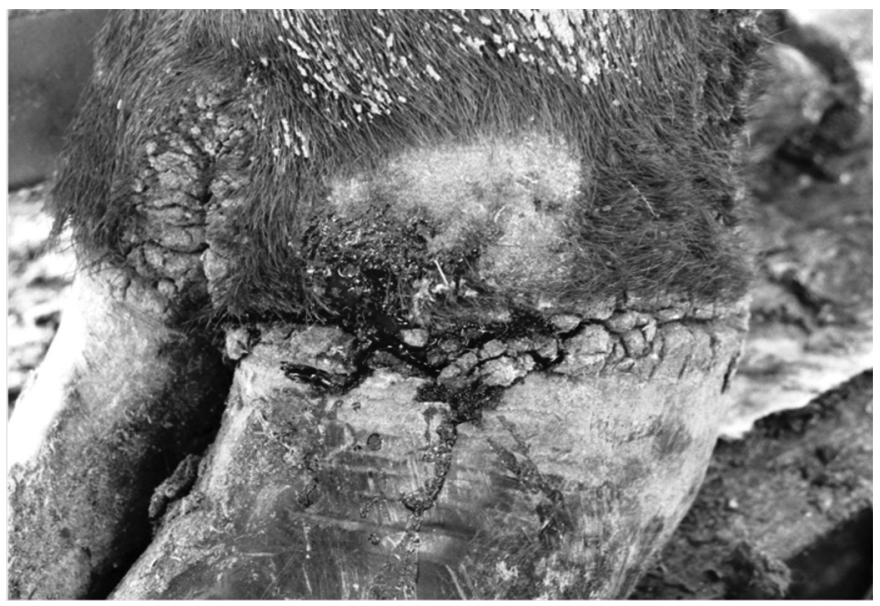

Fig.5. Dermatite em bovino associada ao consumo de farelo de arroz desengordurado. Na grande maioria dos animais afetados as lesões atingem a coroa do casco.

até 1,0 cm de espessura, que podem rachar e precipitar infecção bacteriana secundária (Dutra 1998).

Nas seções histológicas examinadas observava-se um moderado a acentuado infiltrado inflamatório. Esse infiltrado estava localizado principalmente ao redor de vasos sanguíneos superficiais, espalhando-se pela derme. Era constituído predominantemente de linfócitos e histiócitos (Fig.7). Através da coloração do Azul de Toluidina não foi evidenciado aumento dos mastócitos dérmicos. Em uma área focalmente extensa da epiderme havia marcado acúmulo de células inflamatórias degeneradas e de ceratinócitos entremeados por sangue e fibrina (crosta serocelular). Havia acentuada hiperplasia da epiderme (acantose e hiperceratose ortoceratóica) (Fig.8).

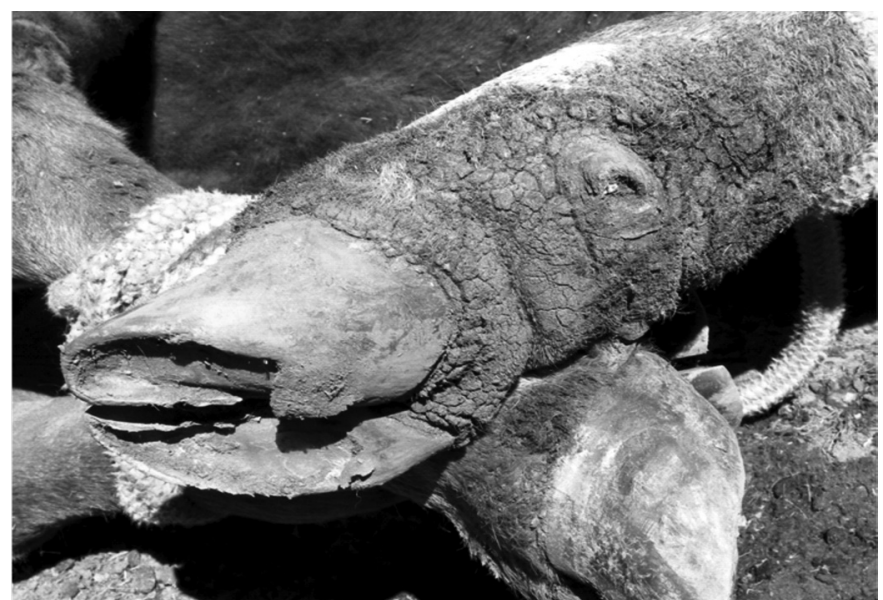

Fig.6. Dermatite associada ao consumo de farelo de arroz desengordurado. Bovino com lesão acentuada, estendendo-se proximalmente e atingindo a região do dígito acessório.

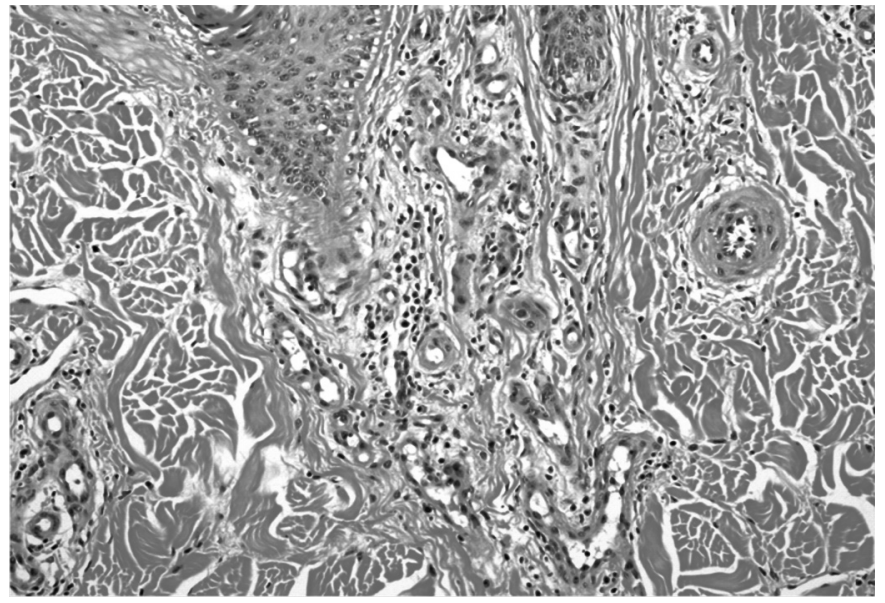

Fig.7. Dermatite em bovino associada ao consumo de farelo de arroz desengordurado. Pele: observa-se ao redor dos vasos sanguíneos superficiais da derme moderado infiltrado inflamatório, constituído de linfócitos e raros plasmócitos. HE, obj.20x.

A literatura (Dutra \& Cesar 2000) descreve dois padrões histológicos para esta enfermidade: (1) um agudo, caracterizado por infiltrado perivascular constituído por linfócitos, histiócitos e eosinófilos, com marcado edema dérmico, espongiose e formação de vesículas; (2) e outro denominado de crostoso, com acentuada formação de crostas serocelular, hiperplasia da epiderme e infiltrado perivascular predominantemente mononuclear. No nosso estudo, devido ao tempo das lesões, o tipo observado era o crostoso.

o padrão de lesão descrito (dermatite perivascular) é típico de reações de hipersensibilidade (Cianferoni \& Spergel 2009, Gross et al 2009). Apesar do mecanismo da hipersensibilidade alimentar ainda não estar totalmente claro, reações de hipersensibilidade tipo I tem sido incriminados e reações do tipo IV também tenham sido suspeitadas (Halliwell 1992, Sampson 1999, Scott \& Miller 2003, Schild 2007). Embora alguns autores descrevam eosinófilos como as principais células envolvidas (Scott \& Miller 2003, Scott et al 2001), um livro de referência em dermatopatias de pequenos animais (Gross et al 2009) descreve uma dermatite perivascular puramente mononuclear em gatos com hiper- 


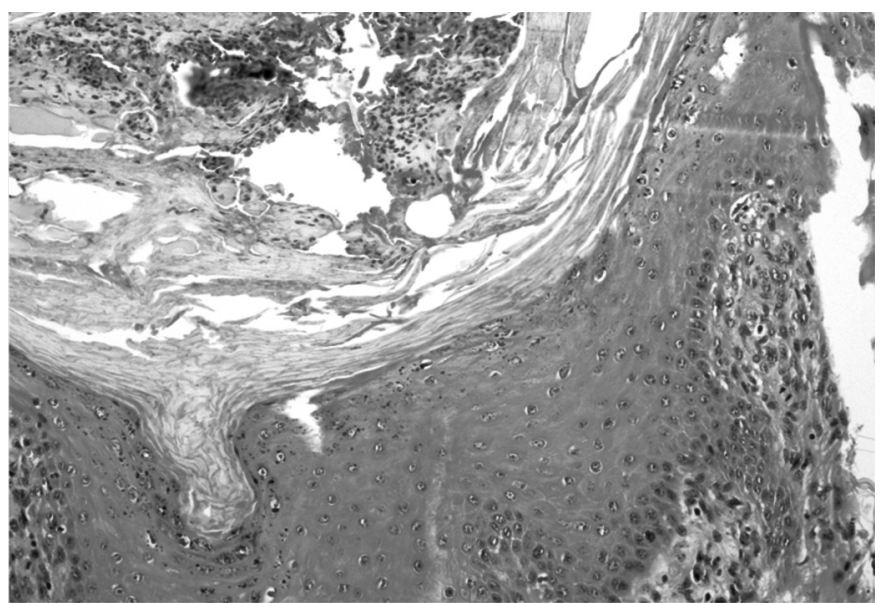

Fig.8. Dermatite em bovino associada ao consumo de farelo de arroz desengordurado. Pele: na epiderme há formação de crosta serocelular e acentuada acantose e hiperceratose ortoceratóica. HE, obj.20x.

sensibilidade alimentar. 0 nosso grupo (dados não publicados) tem observado que algumas lesões de equinos com dermatopatias alérgicas, embora não se saiba a causa concreta, são quase que exclusivamente linfocíticas.

Não foram observadas alterações no eritrograma e nem no leucograma dos sete bovinos acometidos. Na dosagem das proteínas séricas totais observou-se moderado aumento. Além disso, havia uma diminuição na concentração sérica da albumina, com consequente aumento das globulinas devido a maior concentração das gamaglobulinas, em pequenas proporções; porém, a concentração de IgE estava dentro dos limites normais, assim como nos bovinos controles. Acreditamos que este aumento das gamaglobulinas se deve provavelmente a uma resposta aos estímulos causados pela exposição aos diversos tipos de antígenos aos quais os animais estão constantemente expostos, não tendo relação com a doença aqui descrita.

$\mathrm{Na}$ atopia, uma clássica reação de hipersensibilidade tipo I, não há elevação dos níveis de IgE no soro de cães e humanos acometidos, nem alterações no hemograma (Walton 1971, Scott et al 2001, Scott \& Miller 2003). Isto pode ser explicado pelo fato que níveis mínimos de IgE são capa- zes de desencadear a doença (Barratt \& Porter 1979, Scott et al 2001, Tizard 2002, Sicherer \& Sampson 2009), o que pode ter acontecido com estes bovinos. Outra hipótese é o padrão crônico que as lesões apresentavam. A não observação do aumento do número de mastócitos dérmicos, nos leva a crer que a reação estava em decadência.

No Uruguai descreve-se (Dutra 1998) o teste intradérmico para determinar se os animais que consumiram o FAD e desenvolveram as lesões se tornam hipersensíveis as proteínas presentes no mesmo. Esse autor obteve um aumento de $0,25 \mathrm{~cm}$ entre as duas medições. Já nos controles o aumento foi de $0,30 \mathrm{~cm}$ entre as duas horas. No surto descrito aqui, quando o teste foi realizado, os animais já haviam parado a ingestão da ração há 30 dias e as lesões haviam regredido espontaneamente. A pele se apresentava intacta e sem resquícios da lesão (Fig.9). Em um dos animais, a espessura da prega aumentou $0,50 \mathrm{~cm}$ entre cada medição; já no outro bovino, obteve-se $0,60 \mathrm{~cm}$ de aumento entre T0 e T1 e $0,90 \mathrm{~cm}$ na segunda hora (entre T1 e T2). No bovino controle, na primeira hora (entre T0 e T1) houve um aumento significativo de $0,70 \mathrm{~cm}$, porém este se manteve constante na segunda hora. Estes resultados mostram que os animais desenvolvem hipersensibilidade e reação às proteínas e, se fossem observados por alguns dias, haveria grandes chances de desenvolverem a doença, como descrito (Dutra 1998).

Hipersensibilidade alimentar é raramente descrita em bovinos (Van Dijk et al 1988, Hensel 2010). Além do farelo de arroz, outros alimentos incriminados são farelo de trigo, milho, feno de trevo e soja (Ginn et al 2007), e ainda assim, provocando reações gastrointestinais na maioria das vezes (Van Dijk et al 1988). Dermatite, além de alterações em outros sistemas, tem sido descrita em bovinos, suínos, equinos e bubalinos que ingerem batata (Radostitis et al 2007). Em um surto descrito em búfalos, as lesões secundárias à ingestão de batata também se restringem aos membros posteriores, úbere e base da cauda (Somvanshi et al 1992). Outra enfermidade que cursa com lesões extremamente semelhantes é a deficiência de zinco, comumente observada em suínos, mas também descrita em bovinos na forma subclínica ou hereditária (Tokarnia et al 2000, Hensel 2010).
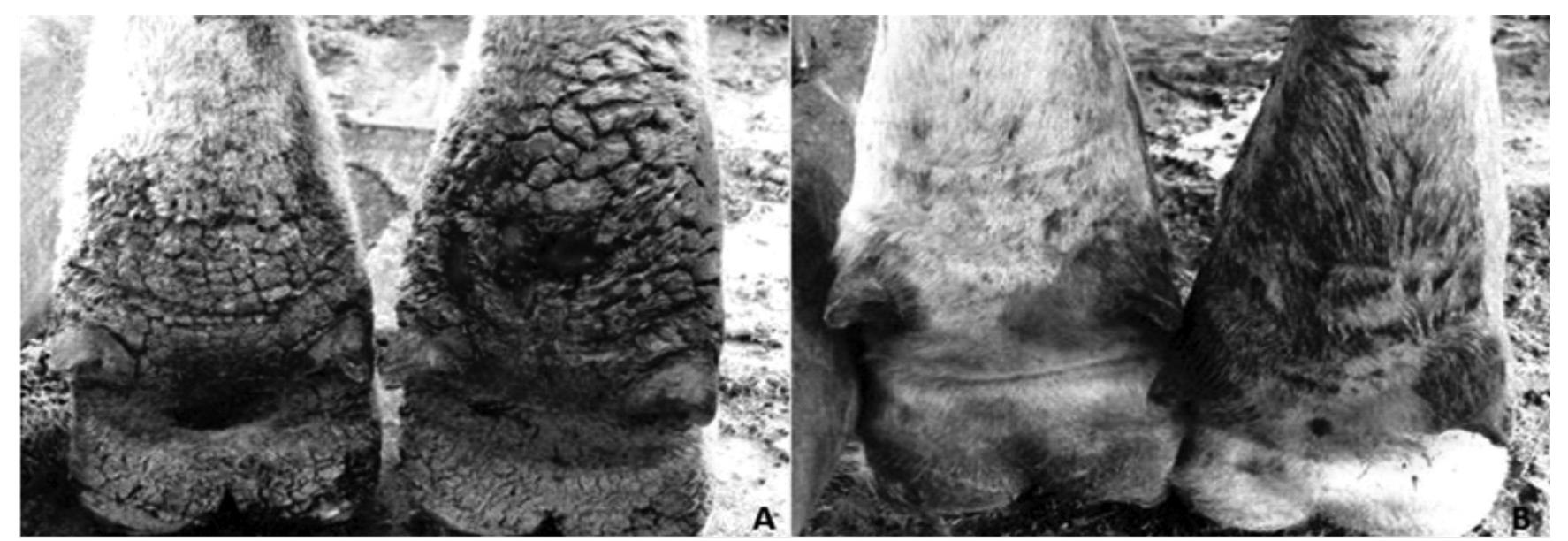

Fig.9. Dermatite em bovino associada ao consumo de farelo de arroz desengordurado. (A) Lesão acentuada e (B) melhora completa e espontânea após 30 dias. 
Algumas dermatopatias bacterianas, como dermatofitose e foliculite estafilocócica, sarna sarcóptica e besnoitiose causam lesões macroscópicas semelhantes, porém, não se restringem aos membros dos animais e suas lesões histológicas são características (Radostitis et al 2007, Scott 2007). Vasculite idiopática é uma condição raramente relatada em bovinos, mas que também cursa com lesões nos membros (Scott 2007) e dermatite necrolítica superficial (síndrome hepatocutânea), descrita em cães e rara em gatos, apresenta-se macroscopicamente semelhante, embora afete várias partes do corpo (Ginn et al 2007).

\section{CONCLUSÕES}

Os dados epidemiológicos, as lesões macroscópicas e os achados histológicos são suficientes para a confirmação do diagnóstico. Dados sobre a doença são extremamente escassos na literatura brasileira e no Uruguai. A fácil disponibilidade e uma expectativa de maior oferta deste produto no decorrer dos próximos anos fazem do farelo de arroz desengordurado um alimento de grande valor como suplemento para a criação de bovinos. Porém, o aparecimento da enfermidade ocasiona perdas econômicas tanto para os produtores, quanto para a indústria e conspira contra a adoção desta nova tecnologia. Dessa forma, acreditamos que com a descrição desta doença, ajudamos a encontrar um uso racional para tal produto, lembrando da importância da adaptação alimentar quando se opta pela suplementação e de seguir as recomendações de dosagem que o fabricante oferece.

Agradecimento: Ao Progama Nacional de Cooperação Acadêmica (PROCAD) pelo suporte financeiro.

\section{REFERÊNCIAS}

Barratt M.E.J. \& Porter P. 1979. Immunoglobulin classes implicated in intestinal disturbances of calves associated with soya protein antigens, J. Immunol. 123:676-680.

Belyea R.L., Steevens B.J., Restrepo R.J. \& Clubb A.P. 1989. Variation in composition of by-product feeds. J. Dairy Sci. 72:2339-2345.

Cianferoni A. \& Spergel M. 2009. Food Allergy: Review, classification and diagnosis. Allergology International 58:457-466.

Costa N.L., Townsend C.R. \& Magalhães J.A. 2005. Informativo Embrapa, Brasília, DF.

Dutra F. 1998. Investigación sobre la causa y patogenesis de la dermatitis en bovinos causada por el afrechillo de arroz desgrasado. Instituto Nacional de Investigacion Agropecuária (INIA), Serie Técnica n.95, Montevideo, Uruguay. $22 \mathrm{p}$.

Dutra F. \& Cesar D. 2000. Allergic dermatitis in cattle fed defatted rice bran, Anais XXI World Buiatric Congress y XXVII Uruguayan Buiatrics Journey, Punta del Este, Uruguay. 8p.

Forster L.A., Goetsch A.L., Galloway D.L., Sun W., Patil A.R. \& Johnson Z.B. 1994. Digestion characteristics, feed intake and live weight gain by cattle consuming forage supplemented with defatted rice bran or other feedstuffs. Anim. Feed Sci. Technol. 47:259-275.

Garcia D.C., Newbold C.J., Galbraith H. \& Topps H. 1992. The effect of including Colombian rice polishings in the diet on rumen fermentation in vitro. Anim Prod. 54:275-280.

Garcia D.C., Newbold C.J., Galvraith H., Topps J.H., Chen X.B. \& Rooke A. 1993. Rice polishings as an alternative to sugar cane molasses as a supplement with to low-quality forage diets for ruminants. Anim. Product. 56:85-92.

Ginn P.E., Mansell J.E.K.L \& Rakich P.M. 2007. Skin and appendages, p.354-
357. In: Maxie M.G. (Ed.), Jubb, Kennedy, and Palmer's Pathology of Domestic Animals. Vol.1. $5^{\text {th }}$ ed. Saunders Elsevier, Philadelphia.

Gross T.L., Ihrke P.J., Walder J.E. \& Affolter K.V. 2009. Doenças de pele do cão e do gato: diagnóstico clínico e histopatológico. Roca, São Paulo. $889 \mathrm{p}$.

Halliwell R.E.W. 1992. Comparative aspects of food intolerance. Vet. Med. 87:893-899.

Hensel P. 2010. Nutrition and skin diseases in veterinary medicine. Clinics in Dermatology 28:686-693.

Irgovel Rações s/d. Bovinos de Corte. Informativo Técnico, Indústria Riograndense de Óleos Vegetais, Pelotas. 18p.

Leite D.T. 2006. Farelo de arroz desengordurado e farelo de glúten de milho na suplementação de bovinos de corte. Dissertação de Mestrado em Zootecnia, UFSM, Santa Maria, RS. 74p.

Li D.F., Nelssen J.L., Reddy P.G., Blecha F., Hancock J.D., Allee G.L., Googband R.D. \& Klemm R.D. 1990. Transiente hypersensitivity to soybean meal in the early-weaned pig. J. Anim. Sci. 68:1790-1799.

Ørskov E.R. \& McDonald I. 1979. The estimation of protein degradability in the rumen from incubation measurements weighted according to rate of passage. J. Agricult. Sci. 92:499-503.

Prasad C.S., Sampath K.T., Shivaramaiah M.T. \& Sampath S.R. 1990. Nutrient utilization studies in growing crossbred calves fed acid-treated deoiled rice bran in their ration. Indian J. Anim. Sci.11:1360-1363.

Radostits O.M., Gay C.C., Hinchcliff K.W. \& Constable P.D. 2007. Diseases of the skin, conjunctiva, and external ear, p.651-671. In: Ibid. (Eds),Veterinary Medicine: A textbook of the diseases of cattle, horses, sheep, pigs and goats. $10^{\text {th }}$ ed. Saunders Elsevier, Edinburgh, Scotland.

Sampson H.A. 1999. Food allergy. 1. Immunopathogenesis and clinical disorders. J. Allergy Clin. Immunol. 103:717-728.

Schild A.L. 2007. Dermatite associada ao consumo de farelo de arroz desengordurado, p.27-30. In: Riet-Correa F., Schild A.L., Lemos R.A.A. \& Borges J.R.J. (Eds), Doenças de Ruminantes de Equídeos. Vol.2. $3^{\mathrm{a}}$ ed. Pallotti, Santa Maria, RS.

Schild A.L., Riet-Correa F., Pereira D.B., Ladeira R., Raffi M.B., Andrade G.B. \& Schuch L.F. 1997. Doenças diagnosticadas pelo Laboratório Regional de Diagnóstico no ano de 1996. Bolm Laboratório Regional de Diagnóstico no 17 , Pelotas, RS. 94p.

Sicherer S.H. \& Sampson H.A. 2009. Food Allergy: Recent advances in pathophysiology and treatment. Annual Rev. Med. 60:261-277.

Scott D.W. 2007. Color Atlas of Farm Animal Dermatology. Blackwell, Iowa. $252 \mathrm{p}$.

Scott D.W., Miller Jr W.H. \& Griffin C.E. 2001. Muller and Kirk's Small Animal Dermatology. $6^{\text {th }}$ ed. W.B Saunders, Philadelphia. 1528p.

Scott D.W. \& Miller Jr W.H. 2003. Equine Dermatology. W.B. Saunders, St Louis. 823p.

Somvanshi R., Biswas J.C. \& Sastry M.S. 1992. Potato plant (Solanum tuberosum) induced dermatitis in Indian buffaloes. Indian J. Anim. Sci. 62:639-641.

Tizard I.R. 2002. Imunologia Veterinária: uma introdução. $6^{\text {th }}$ ed. Roca, São Paulo. 532p.

Tokarnia C.H., Döbereiner J. \& Peixoto P.V. 2000. Deficiências minerais em animais de fazenda, principalmente bovinos em regime de campo. Pesq. Vet. Bras. 20:127-138.

Van Dijk J.E., Fledderus A., Mouwen J.M. \& Holzhauer C. 1988. Gastrointestinal food allergy and its role in large domestic animals. Vet. Res. Commun. 12:47-59.

Walton G.S. 1971. Allergic responses involving the skin of domestic animals. Adv. Vet. Sci. Comp. Med. 5:201-240.

White W.T. \& Hembry F.G. 1985. Rice by-products in ruminant rations. Louisiana Agricultural Experimental Station, Louisiana, USA.

Zinn R.A., Dunbar J.R. \& Norman B.B. 1988. Influence of pelleting on the comparative feeding value of cottonseed meal in receiving diets for feedlot calves. J. Anim. Sci. 66:1335-1339. 